Research Article

\title{
Relationship between Ineffective Attitudes and General Health in Patients with Chronic Renal Disease Undergoing Hemodialysis in a Hospital in Gorgan, Iran
}

\author{
Firoozeh Derakhshanpour $^{1}$ (D) Zanireh Salimi $^{2}$ (D) Farzaneh Shekhnejad $^{1}$, Najmeh \\ Shahini $^{1}$ (D), Mohammadzaman Kamkar ${ }^{1 *}$
}

1.Golestan Research Center of Psychiatry, Golestan University of Medical Sciences, Gorgan, Iran 2.Psychiatry and Behavioral Sciences Research Center, Mashhad University of Medical Sciences, Mashhad, Iran

*Correspondence: Dr Mohammadzaman Kamkar, Golestan Research Center of Psychiatry (GRCP), Golestan University of Medical Sciences, Gorgan, Iran

Email:kamkar72@yahoo.com

Received January 20, 2021

Accepted March 1, 2021

\begin{abstract}
Background and objectives: Chronic kidney disease (CKD) is a major public health problem worldwide. Hemodialysis (HD) is the most common method of treating CKD. Dysfunctional attitudes play a major role in cognitive vulnerability and general health of HD patients. The aim of this study was to investigate relationship between dysfunctional attitudes and general health of patients with CKD undergoing HD.

Methods: This cross-sectional study was performed on CKD patients undergoing HD at a hospital in Gorgan, Iran during 2018. Overall, 126 patients (69 men and 57 women) aged 15-89 years old were enrolled via simple random sampling. Data were collected using the General Health Questionnaire-28 (GHQ-28), the Dysfunctional Attitude Scale-A (DAS-A) questionnaire and a demographic questionnaire. Collected data were analyzed by SPSS software (version 22) using the Kolmogorov-Smirnov test and Pearson correlation coefficient.
\end{abstract}

Results: The mean age of the participants was $54.9 \pm 13.9$ years old. Mean score of dysfunctional attitudes in HD patients was 26.32 \pm 9.9 , which indicated dysfunctional attitudes. The mean score of GHQ-28 questionnaire was $26.77 \pm 10.44$, indicating low general health. There was a direct and statistically significant relationship between the score of dysfunctional attitudes and the GHQ-28 scores $(\mathrm{P}<0.001)$.

Conclusion: The results of this study showed a direct and significant relationship between dysfunctional attitudes and general health disorder in CKD patients undergoing HD.

Keywords: Dysfunctional attitudes; General health; Dialysis; Chronic kidney disease

DOI: 10.29252/Jcbr.5.1.22

(c) (1) (3)

This work is licensed under a Creative Commons Attribution 4.0 License.

(C) The authors 


\section{INTRODUCTION}

Chronic kidney disease (CKD) is a global health problem defined as glomerular filtration rate (GFR) of below $60 \mathrm{ml} / \mathrm{min}$ per $1.73 \mathrm{~m} 2$ or presence of markers of kidney damage for at least three months $(\underline{1}, \underline{2})$. Currently more than 400 million individuals have CKD in the world (3). The global prevalence of CKS was reported to be $13.4 \%$ (4). The prevalence of CKD was reported to increase by $19.6 \%$ in the past decade (5). Based on a meta-analysis, the prevalence of CKD in Iran was $15.14 \%$, with a 1.7 times higher prevalence in females compared to males (ㅁ) . A common treatment for CKD is hemodialysis, which has increased life expectancy in these patients but may interfere with their daily life activities ( $\underline{8}-\underline{10})$. Reduced quality of life may result in mental disorders, including depression, malnutrition and increased mortality (11).

According to the World Health Organization (WHO), quality of life is the individual's perception of the status of life in terms of cultural and social values in line with personal goals, expectations, standards and desires (12). As HD patients might have different life expectations, they might have different perceptions about the quality of life (13). Patient attitudes is the core concept in HD patient management (14). Therefore, unsatisfactory quality of life might affect adherence to treatment in CKD patients $(\underline{15}$, 16).

The prevalence of depression and anxiety is high among HD patients (17). Depression and anxiety can have negative effects on patient outcome by affecting patient follow up visits and behavior change (18). Therefore, it is important to assess dysfunctional attitudes in HD patients in predicting depressive disorders $(\underline{19}, \underline{20})$. To the best of our knowledge, few studies have assessed the relationship between dysfunctional attitudes toward life and general health in HD patients. Therefore, the aim of this study was to assess dysfunctional attitudes of HD patients and their relationship with general health in a hospital in Gorgan, Iran.

\section{MATERIALS AND METHODS}

Subjects and design

This cross-sectional study was conducted on CKD patients undergoing $\mathrm{HD}$ in the Nephrology Department of the 5 Azar Hospital (Gorgan, Iran) in 2018. Sample size was calculated based on the findings of a similar study (21) considering the correlation coefficient of 0.26 , type one error of 0.05 and type two error of 0.8 . The sample size was calculated as 114 patients. Considering 10\% drop-out, the sample size was determined as 126 patients. The study was approved by the Ethics Committee of the Golestan University of Medical Sciences (ethics code: IR.GOUMS.REC.1398.213). All patients (69 men and 57 women) signed a written informed consent before participating in the study. Recruitment of the subjects was performed based on simple random sampling.

The inclusion criteria were being diagnosed with CKD by a nephrologist, undergoing HD, age range of 15 to 89 years old, literacy and willingness to participate in the study. Exclusion criteria were positive history of severe psychotic diseases including psychosis, severe cognitive impairments as well as chronic diseases including physical disability, cardiovascular disease and severe skin disorders.

Data collection instruments included a demographic questionnaire, the 28-item General Health Questionnaire (GHQ-28) (22) and the 26-item Depression Anxiety and Stress (DASS-26) questionnaire (23). The questionnaires were filled for all subjects.

\section{Study instruments}

The demographic including patient age, gender, education level and place of residence and present and past medical 
history (duration of dialysis and dialysis frequency) were collected using the demographic questionnaire.

The GHQ-28 includes four subscales that assess the individual's psychological status during the past month. The subscales include physical symptoms, anxiety and insomnia, social performance disorders, and depression. Each subscale consists of seven questions that are scored based on a 4-point Likert scale. The total score can range from zero to 84 with higher scores indicating worst quality of life. The GHQ-28 subscale scores higher than six and the total score higher than 22 are considered abnormal. The questionnaire was validated on Iranian population with the Cronbach's alpha of $0.93(\underline{24}, \underline{25})$.

The Dysfunctional Attitude Scale form A (DAS-A) questionnaire is a summarized form of the primary DAS-40 questionnaire. DAS-A items are scored based on a 7-point Likert scale (26). Total DASS-26 scores may range from 26 to a 82 with higher scores indicating worst condition. The psychometric analysis of the DAS-A was assessed previously on Iranian population with Cronbach's alpha of $0.92(\underline{27})$.

Statistical analysis

Data analysis was performed using the Statistical Package for Social Sciences (SPSS) software (version 22). The Kolmogorov-Smirnov test was used to check the normality of data. The mean and standard deviation (SD) were used to describe continuous data. The Pearson correlation coefficient was used to assess the correlation between study variables. All statistical analyses were performed at statistical significance of 0.05 .

\section{RESULTS}

The mean age of the patients was $54.9 \pm$ 13.9 years. Table 1 shows the mean scores for dysfunctional attitude subscales of the study patients.

Table 1. The mean scores for dysfunctional attitude subscales among patients undergoing hemodialysis

\begin{tabular}{|c|c|c|}
\hline Subscale & Score range & Mean \pm SD \\
\hline Perfectionism & $4-28$ & $4.40 \pm 1.90$ \\
\hline Need for others approval & $5-35$ & $6.01 \pm 2.40$ \\
\hline Need to satisfy others & $4-28$ & $2.80 \pm 2.03$ \\
\hline Vulnerability-Functional evaluation & $13-91$ & $13.07 \pm 5.50$ \\
\hline Total score & $26-182$ & $26.32 \pm 9.90$ \\
\hline
\end{tabular}

Table 2 shows the mean score for GHQ-28 subscales in the study patients.

Table 2. Mean scores for GHQ-28 and its subscales among patients undergoing hemodialysis

\begin{tabular}{|c|c|c|c|}
\hline Subscale & Score range & Mean \pm SD & Severity \\
\hline Somatic symptoms & $0-21$ & $7.16 \pm 3.40$ & Mild \\
\hline Anxiety and insomnia symptoms & $0-21$ & $7.02 \pm 3.70$ & Mild \\
\hline Social performance & $0-21$ & $9.07 \pm 2.60$ & Mild \\
\hline Depressive symptoms & $0-21$ & $3.52 \pm 3.50$ & Minimum \\
\hline Total score & $0-84$ & $26.77 \pm 10.44$ & Mild \\
\hline
\end{tabular}


The correlation between dysfunctional attitudes and general health based on the study categories is presented in table 3 . There was a significant correlation between dysfunctional attitudes and GHQ-28 scores and dysfunctional attitudes $(\mathrm{r}=0.322$, $\mathrm{P}<0.001)$. The correlation between dysfunctional attitudes and GHQ-28 was significant with male gender $(\mathrm{r}=0.30$,
$\mathrm{P}=0.011)$, residence in urban areas $(\mathrm{r}=0.30$, $\mathrm{P}=0.004)$, illiteracy and primary school education level $(\mathrm{r}=0.59, \quad \mathrm{P}=0.001), \quad 3-4$ dialysis sessions per week $(r=0.38$, $\mathrm{P}<0.001), 1-3$ years of dialysis $(\mathrm{r}=0.34$, $\mathrm{P}=0.003)$, age of $31-34$ years old $(\mathrm{r}=0.56$, $\mathrm{P}=0.006)$ and age of $46-60$ years old $(\mathrm{r}=0.39, \mathrm{P}=0.004)$.

Table 3. Correlation between dysfunctional attitudes and general health among patients undergoing hemodialysis

\begin{tabular}{|c|c|c|c|c|}
\hline \multirow{2}{*}{\multicolumn{2}{|c|}{ Variable }} & \multirow{3}{*}{$\begin{array}{c}\text { Frequency (\%) } \\
69(54.8 \%) \\
\end{array}$} & \multicolumn{2}{|c|}{ Correlation } \\
\hline & & & $\mathrm{r}$ & $\mathrm{P}$-value \\
\hline \multirow{2}{*}{ Gender } & Male & & 0.30 & $0.011 *$ \\
\hline & Female & $57(45.2 \%)$ & 0.006 & 0.36 \\
\hline \multirow{2}{*}{ Place of residence } & Rural & $36(28.6 \%)$ & 0.166 & 0.34 \\
\hline & Urban & $90(71.4 \%)$ & 0.30 & $0.004 *$ \\
\hline \multirow{5}{*}{ Education level } & $\begin{array}{c}\text { Illiterate or } \\
\text { primary }\end{array}$ & $30(23.8 \%)$ & 0.59 & $0.001 *$ \\
\hline & $\begin{array}{l}\text { Primary } \\
\text { graduate }\end{array}$ & $52(41.3 \%)$ & 0.41 & 0.41 \\
\hline & Secondary & $31(24.6 \%)$ & 0.30 & 0.10 \\
\hline & Diploma & $6(5.0 \%)$ & 0.79 & 0.79 \\
\hline & $\begin{array}{l}\text { Graduate } \\
\text { and post- } \\
\text { graduate }\end{array}$ & $7(5.3 \%)$ & 0.59 & 0.29 \\
\hline \multirow{2}{*}{ Dialysis frequency } & $\begin{array}{l}\text { 1-2 times a } \\
\text { week }\end{array}$ & $36(28.6 \%)$ & 0.55 & 0.10 \\
\hline & $\begin{array}{l}\text { 3-4 times } \\
\text { week }\end{array}$ & $90(71.4 \%)$ & 0.38 & $<0.001^{*}$ \\
\hline \multirow{5}{*}{$\begin{array}{l}\text { Dialysis duration } \\
\text { (years) }\end{array}$} & $0-1$ & $10(7.9 \%)$ & 0.13 & 0.73 \\
\hline & $1-3$ & $72(57.1 \%)$ & 0.34 & $0.003^{*}$ \\
\hline & $3-6$ & $30(23.8 \%)$ & 0.23 & 0.23 \\
\hline & $6-9$ & $8(6.3 \%)$ & 0.52 & 0.18 \\
\hline & $9-12$ & $6(4.8 \%)$ & 0.54 & 0.27 \\
\hline \multirow{5}{*}{ Age (years) } & $15-30$ & $6(4.8 \%)$ & 0.62 & 0.19 \\
\hline & $31-45$ & $23(18.3 \%)$ & 0.56 & $0.006^{*}$ \\
\hline & $46-60$ & $51(40.5 \%)$ & 0.39 & $0.004 *$ \\
\hline & $61-75$ & $38(30.2 \%)$ & 0.18 & 0.29 \\
\hline & $76-90$ & $8(6.3 \%)$ & 0.41 & 0.34 \\
\hline
\end{tabular}

* Significant correlation

\section{DISCUSSION}

The findings of this study revealed that the mean score for dysfunctional attitudes was relatively low among HD patients, while all the DAS-A subscales were low for all patients. Similarly, the mean general health score of the subjects was less than half the achievable score. Our study findings indicated that dysfunctional attitudes and general health were significantly correlated in CKD patients undergoing HD. This finding indicates that the general health score increased with the increase in dysfunctional attitudes score, which was only significant among patients aged 31 to 45 and 46 to 60 years old.

In contrast to the findings of our study, a 
previous study showed that dysfunctional attitude scores were above medium in renal transplantation patients (28). The reason for this difference might be due to the difference between study participants. Unlike the patients in our study, the patients in the mentioned study were transplant patients who may have gone through more negative experiences and therefore reported higher attitudes compared to our study patients. The findings of our study also indicated that the mean general health score of the subjects was low, almost less than half the achievable score. Similarly, the mean score in all subscales of the GHQ-28 questionnaire were low among our subjects. Inconsistent with our findings, another study on HD and transplant patients showed that the mean general health score of the patients were higher than half of the maximum achievable score (29). This difference might be due to the difference in terms of subjects' education level as the participants in the mentioned study were mostly $(82.2 \%)$ illiterate or had primary school education level, while only $23.8 \%$ of our subjects were illiterate or had primary school education. The findings of our study regarding the correlation between dysfunctional attitudes and general health was in line with the findings of previous studies on Iranian renal transplant patients $(\underline{28}, \underline{30})$. We observed that the correlation between dysfunctional attitudes and general health was significant only among male patients, which is in agreement with findings of a study by Gutteling et al. (31). Furthermore, the correlation between dysfunctional attitudes and general health score was only significant among residents in urban areas, which is in line with the findings of some previous studies $(\underline{32}, \underline{33})$. This could be due to the fact that rural patients generally have a better socioeconomic status and family support; therefore, they have less dysfunctional attitudes toward their health. In line with some previous studies, we observed that the correlation between dysfunctional attitudes and general health was significant in patients who were illiterate or had primary school education $(\underline{34}, \underline{35})$. It is hypothesized that patients with a higher level of education may be more hopeful towards their treatment outcome and have a higher health level compared to patients with a lower education level. We also found a significant correlation between poor general health and dysfunctional attitudes among HD patients, which is in agreement with findings of previous studies $(\underline{36}, \underline{37})$. We also observed a significant correlation between dysfunctional attitudes and poor general health scores among patients who were on HD 3 to 4 times a week. This finding was in line with the findings of a previous studies $(\underline{38}, 39)$. The high frequency of dialysis sessions might cause stress and increase dysfunctional attitudes in the patients. There was also a significant correlation between dysfunctional attitudes and poor general health in patients who were under HD for one to three years. This finding was in line with the findings of a previous study ( $\underline{38})$. Dialysis duration might affect psychological wellbeing of the patients and result in psycho-somatic disorders that may result in dysfunctional attitudes (40, $\underline{41})$. Furthermore, age range of 31-45 years and 46-60 years were significantly correlated with dysfunctional attitudes and poor general health, which is in line with findings of a previous study (32). It is possible that these patients may experience more frustration and hopelessness compared to patients in other age groups, as usually individuals are active and efficient.

One of the limitations of this study was lack of a definite diagnosis of depression, anxiety and stress as the DASS questionnaire was not designed to diagnose these mental conditions. Therefore, it is recommended to conduct further studies while considering presence of mental disorders and their relationship with dysfunctional attitudes among HD patients.

\section{CONCLUSION}

Our findings indicated a significant and 
positive correlation between dysfunctional attitudes and poor general health among CKD patients undergoing HD. Based on the results, there may an urgent need for behavioral interventions to improve attitudes of HD patients towards life and health.

\section{ACKNOWLEDGEMENTS}

The authors would like to thank all those who helped us in this study.

\section{DECLARATIONS \\ Funding}

Not applicable.

\section{Ethics approvals and consent to participate}

The study was approved by the ethics committee of Golestan University of Medical Sciences, Gorgan, Iran (ethics code: IR.GOUMS.REC.1398.213). A written informed consent was obtained from all subjects prior to participation.

\section{Conflict of interest}

The author declares that there is no conflict of interest regarding publication of this article.

\section{REFERENCES}

1. Goolsby MJ. National Kidney Foundation Guidelines for chronic kidney disease: evaluation, classification, and stratification. Journal of the American Academy of Nurse Practitioners. 2002;14(6):238-42. [View at Publisher] [DOI] [PubMed] [Google Scholar]

2. Golshayan D, Pascual M. Burden of end-stage renal disease and evolving challenges in kidney transplantation. Transplant International. 2019;32(9):889-91. [View at Publisher] [DOI] [PubMed] [Google Scholar]

3. Mills KT, Xu Y, Zhang W, Bundy JD, Chen C-S, Kelly TN, et al. A systematic analysis of worldwide population-based data on the global burden of chronic kidney disease in 2010. Kidney international. 2015;88(5):950-7. [View at Publisher] [DOI] [PubMed] [Google Scholar]

4. Hill NR, Fatoba ST, Oke JL, Hirst JA, O'Callaghan CA, Lasserson DS, et al. Global prevalence of chronic kidney disease-a systematic review and metaanalysis. PloS one. 2016;11(7):e0158765. [View at Publisher] [DOI] [PubMed] [Google Scholar]

5. Kassebaum NJ, Arora M, Barber RM, Bhutta ZA, Brown J, Carter A, et al. Global, regional, and national disability-adjusted life-years (DALYs) for 315 diseases and injuries and healthy life expectancy (HALE), 1990-2015: a systematic analysis for the Global Burden of Disease Study 2015. The Lancet. 2016;388(10053):160358. [View at Publisher] [DOI] [PubMed] [Google Scholar]

6. Bouya S, Balouchi A, Rafiemanesh H, Hesaraki M. Prevalence of Chronic Kidney Disease in Iranian General Population: A Meta-Analysis and Systematic Review. Therapeutic apheresis and dialysis. 2018;22(6):594-9. [View at Publisher] [DOI] [PubMed] [Google Scholar]

7. Beto J, Bhatt N, Gerbeling T, Patel C, Drayer D. Overview of the 2017 KDIGO CKD-MBD update: Practice implications for adult hemodialysis patients. Journal of Renal Nutrition. 2019;29(1):2-15. [View at Publisher] [DOI] [PubMed] [Google Scholar]

8. Neild GH. Life expectancy with chronic kidney disease: an educational review. Pediatric Nephrology. 2017;32(2):243-8. [View at Publisher] [DOI] [PubMed] [Google Scholar]

9. Barbosa JBN, Moura ECSCd, Lira CLOBd, Marinho PÉdM. Quality of life and duration of hemodialysis in patients with chronic kidney disease (CKD): a crosssectional study. Fisioterapia em Movimento. 2017;30(4):781-8. [View at Publisher] [DOI] 


\section{[Google Scholar]}

10. Sousa L, Antunes AV, Baixinho C, Severino S, Marques-Vieira C, José $H$. Subjective Wellbeing Assessment in People with Chronic Kidney Disease Undergoing Hemodialysis. Chronic Kidney Diseasefrom Pathophysiology to Clinical Improvements Croácia: InTech. 2018:28193. [View at Publisher] [DOI] [Google Scholar]

11. AghaKhani N, Sharif F, Sharifnia H, Rahbar N, Parkhashjoy M, Emami A, et al. Application of Orem Self-Care Theory in Nutrition Program Training on Quality of Life in Hemodialysis Patients in Urmia Teaching Hospitals. Journal of Family Health, Faculty of Medicine, Islamic Azad University, Sari Branch. 2013;1(2):47-54. [View at Publisher] [Google Scholar]

12. Saxena S, Orley J, Group W. Quality of life assessment: the World Health Organization perspective. European psychiatry. 1997;12:263s-6s. [View at Publisher] [DOI] [PubMed] [Google Scholar]

13. Naalweh KS, Barakat MA, Sweileh MW, Al-Jabi SW, Sweileh WM, Sa'ed HZ. Treatment adherence and perception in patients on maintenance hemodialysis: a cross-sectional study from Palestine. BMC nephrology. 2017;18(1):178. [View at Publisher] [DOI] [PubMed] [Google Scholar]

14. Joung S-a, Park K-Y. The relationships between knowledge on advance directive, attitudes towards the withdrawal of lifesustaining treatment and quality of life in hemodialysis patients. Journal of Korean Academy of Community Health Nursing. 2017;28(3):291-301. [View at Publisher] [DOI] [Google Scholar]

15. Moonaghi HK, Hasanzadeh F, Shamsoddini S, Emamimoghadam Z, Ebrahimzadeh S. A comparison of face to face and video-based education on attitude related to diet and fluids: Adherence in hemodialysis patients. Iranian journal of nursing and midwifery research. 2012;17(5):360. [View at Publisher] [PubMed] [Google Scholar]

16. Najafi A, Keihani S, Bagheri N, Jolfaei AG, Meybodi AM. Association between anxiety and depression with dialysis adequacy in patients on maintenance hemodialysis. Iranian journal of psychiatry and behavioral sciences. 2016;10(2). [View at Publisher] [DOI] [PubMed] [Google Scholar]

17. Ng HJ, Tan WJ, Mooppil N, Newman $\mathrm{S}$, Griva K. Prevalence and patterns of depression and anxiety in hemodialysis patients: A 12 - month prospective study on incident and prevalent populations. British journal of health psychology. 2015;20(2):374-95. [View at Publisher] [DOI] [PubMed] [Google Scholar]

18. Chan L, Tummalapalli SL, Ferrandino R, Poojary P, Saha A, Chauhan K, et al. The effect of depression in chronic hemodialysis patients on inpatient hospitalization outcomes. Blood purification. 2017;43(13):226-34. [View at Publisher] [DOI] [PubMed] [Google Scholar]

19. Ebrahimi A, Mosavi S. Psychometric Properties of The Dysfunctional Attitude Scale-26 DAS-26) in Patients with Mood Disorders. Scientific Journal of Ilam University of Medical Sciences. 2013;21(5):20-8. [View at Publisher] [Google Scholar]

20. Lam KF, Lim HA, Tan JY, Mahendran RJCp. The relationships between dysfunctional attitudes, rumination, and non-somatic depressive symptomatology in newly diagnosed Asian cancer patients. 2015;61:49-56. [View at Publisher] [DOI] [PubMed] [Google Scholar]

21. Pasha R, Seraj A. The effectiveness of mindfulness-based cognitive therapy on rumination and dysfunctional attitudes in patients with major depressive disorder and obsessive-compulsive disorder. Journal of 
Psychological Achievements, Educational Sciences, and Psychology ,Shahid Chamran University of Ahvaz. 2017;4(25):93-112.

22. Malakouti SK, Fatollahi P, Mirabzadeh A, Zandi T. Reliability, validity and factor structure of the GHQ-28 used among elderly Iranians. International Psychogeriatrics. 2007;19(4):623. [View at Publisher] [DOI] [PubMed] [Google Scholar]

23. Asghari A, Saed F, Dibajnia P. Psychometric properties of the Depression Anxiety Stress Scales-21 (DASS-21) in a non-clinical Iranian sample. Int J psychol. 2008;2(2):82-102. [Google Scholar]

24. Baghianimoghadam MH, Sharifirad G, Rahaei Z, Baghianimoghadam B, Heshmati HJCEjoph. Health related quality of life in children with thalassaemia assessed on the basis of SF-20 questionnaire in Yazd, Iran: a case-control study. 2011;19(3):165. [DOI] [PubMed] [Google Scholar]

25. Ahmadi M, Noudehi M, Esmaeili M, Sadrollahi AJIJoA. Comparing the quality of life between active and non-active elderly women with an emphasis on physical activity. 2017;12(3):262-75. [View at Publisher] [DOI] [PubMed] [Google Scholar]

26. Crawford JR, Henry JD. The Depression Anxiety Stress Scales (DASS): Normative data and latent structure in a large non - clinical sample. British journal of clinical psychology. 2003;42(2):111-31. [View at Publisher] [DOI] [PubMed] [Google Scholar]

27. Ebrahimi A, Afshar H, Doost HTN, Mousavi SG, Moolavi HJJorimstojoIUoMS. Attitude scale and general health questionnaire subscales predict depression? 2012;17(1):40. [View at Publisher] [PubMed] [Google Scholar]

28. RAKRAVA M, OMRANIFARD V, EBRAHIMI A, ATAPOUR A, MORTAZAVI M. Relationship between quality of life, general health and dysfunctional attitudes in kidney transplant patients. 2015. [View at Publisher] [Google Scholar]

29. Masoudi-Alavi N, Sharifi K, AliAkbarzadeh Z. Health status and activities of daily living in hemodialysis and transplant patients. Iran Journal of Nursing. 2011;23(68):47-53. [View at Publisher] [Google Scholar]

30. Aghajani M, Saeidnejad Z, Mirbagher Ajorpaz N. Empowerment Program based on BASNEF Model and the General Health of Hemodialysis Patients. Journal of ClientCentered Nursing Care. 2020;6(1):65-76. [View at Publisher] [DOI] [Google Scholar]

31. Gutteling J, De Man R, Van Der Plas S, Schalm S, Busschbach J, DARLINGTON AS. Determinants of quality of life in chronic liver patients. Alimentary pharmacology \& therapeutics. 2006;23(11):1629-35. [View at Publisher] [DOI] [PubMed] [Google Scholar]

32. Fujisawa M, Ichikawa Y, Yoshiya K, Isotani $\mathrm{S}$, Higuchi $\mathrm{A}$, Nagano $\mathrm{S}$, et al. Assessment of health-related quality of life in renal transplant and hemodialysis patients using the SF-36 health survey. Urology. 2000;56(2):201-6. [View at Publisher] [DOI] [PubMed] [Google Scholar]

33. Maglakelidze N, Pantsulaia T, Tchokhonelidze I, Managadze L, Chkhotua A, editors. Assessment of health-related quality of life in renal transplant recipients and dialysis patients. Transplantation proceedings; 2011: Elsevier. [View at Publisher] [DOI] [PubMed] [Google Scholar]

34. Kallay E, Dégi CL, Vincze AE. Dysfunctional attitudes, depression and quality of life in a sample of Romanian. J Cogn Behav Psychother. 2007;7(1):95-106. [Google Scholar]

35. Bezerra JNdM, Lessa SRdO, Luz GOdA, Borba AKdOT. Health literacy of 
individuals undergoing dialysis therapy. Texto \& Contexto-Enfermagem. 2019;28. [View at Publisher] [DOI] [Google Scholar]

36. Milan M, Nasimi F, Hafizi I, Ghorbanzadeh M, Hosseini Y. Association of spiritual health and quality of life in the hemodialysis patients admitted in Shahid Motahari Hospital in Jahrom, Iran (2016). Iran Journal of Nursing. 2018;31(113):4251. [View at Publisher] [DOI] [Google Scholar]

37. Sousa LMM, Antunes AV, MarquesVieira CMA, Silva PCL, Valentim OMMdS, José HMG. Subjective wellbeing, sense of humor and psychological health in hemodialysis patients. Enfermería Nefrológica. 2019;22(1):34-41. [View at Publisher] [Google Scholar]

38. Mucsi I. Health-Related Quality of Life in Chronic Kidney Disease Patients. Primary psychiatry. 2008;15(1). [View at Publisher] [Google Scholar]
39. Porman Purba TU, Dharmajaya R, Siregar CT. The Effectiveness of Progressive Muscle Relaxation with Benson Relaxation on the Sleep Quality in Hemodialysis Patients. Indian Journal of Public Health Research \& Development. 2020;11(2). [DOI] [Google Scholar]

40. Ryu J-H, Koo TY, Ro H, Cho J-H, Jung $\mathrm{CW}$, Huh $\mathrm{KH}$, et al. Better Health-related Quality of Life in kidney Transplant Patients Compared to Chronic Kidney Disease Patients with Similar Renal Function. 2021. [DOI] [Google Scholar]

41. Paluseri A, Wasir R. Assesment of health-related quality of life with patient chronic kidney disease at hasanuddin university hospital. International Journal of Science, Technology \& Management. 2021;2(1):145-9.

[View at Publisher] [DOI] [Google Scholar]

How to Cite: Derakhshanpour F, Salimi Z, Shekhnejad F, Shahini N, Kamkar M. Relationship between Ineffective Attitudes and General Health in Patients with Chronic Renal Disease Undergoing Hemodialysis in a Hospital in Gorgan, Iran. Journal of Clinical and Basic Research. 2021; 5 (1) :22-30 